\title{
RETRACTED ARTICLE: Epileptic seizure detection by analyzing high dimensional phase space via Poincaré section
}

\author{
R. Shantha Selvakumari ${ }^{1}$ - M. Mahalakshmi ${ }^{1}$
}

Received: 17 March 2017 / Revised: 9 March 2018 / Accepted: 12 May 2018 /

Published online: 19 May 2018

C) Springer Science+Business Media, LLC, part of Springer Nature 2018

The editor has retracted this article because it shows significant overlap with a paper published previously by Zabihi et al. (2016) without proper citation [1]. The authors have not responded to any correspondence regarding this retraction.

The online version of this article contains the full text of the retracted article as electronic supplementary material.

[1] "Analysis of High-Dimensional Phase Space via Poincaré Section for Patient-Specific Seizure Detection". Zabihi, M., Kiranyaz, S., Bahrami Rad, A. et al. IEEE Transactions on Neural Systems and Rehabilitation Engineering (2016). https://doi.org/10.1109/TNSRE. 2015.2505238.

Electronic supplementary material The online version of this article (https://doi.org/10.1007/s11045018-0585-1) contains supplementary material, which is available to authorized users.

\footnotetext{
$\bowtie$ R. Shantha Selvakumari rshantha@mepcoeng.ac.in

M. Mahalakshmi mahalakshmi2446@gmail.com

1 Department of ECE, Mepco Schlenk Engineering College, Sivakasi, India
} 